\title{
MODELING OF MATERIAL BALANCE FROM THE EXPERIMENTAL UCG
}

\author{
Milan Durdán*, JÁn Terpák, JÁn KaČur, Marek LaCiak, \\ PATRIK FLEGNER
}

\author{
Technical University of Košice, Faculty BERG, Institute of Control and Informatization of Production \\ Processes, Němcovej 3, 04001 Košice, Slovak Republic \\ * corresponding author: milan.durdan@tuke.sk
}

\begin{abstract}
The underground coal gasification is a continually evolving technology, which converts coal to calorific gas. There are many important parameters in this technology, which are difficult to measure. These parameters include the underground cavity growth, amount gasified coal, and the leakage of input and output gaseous components into the surrounding layers during the coal gasification process. Mathematical modeling of this process is one of the possible alternatives for determining these unknown parameters. In this paper, the structure of the mathematical model of laboratory underground coal gasification process from the material balance aspect is presented. The material balance consists of mass components entering and leaving from the UCG process. The paper shows a material balance in the form of a general mass balance and atomic species balance. The material balance was testing by six UCG laboratory experiments, which were realized in two ex-situ reactors.
\end{abstract}

KEYWORDS: Underground coal gasification, material balance, atoms, ex-situ reactors, losses.

\section{INTRODUCTION}

The underground coal gasification (UCG) is a continually evolving technology and seems to be a great source of energy that can be obtained at a lower cost than in the case of using conventional mining methods. This process offers a less costly alternative to traditional coal mining methods, especially when the coal seam is placed deep under the earth's surface. A system of two wells needs to be build. At least one for the injection (i.e., for gasification agent input) and at least one for the production (i.e., for product gas output). The UCG is a process of transformation of coal into the output gas (i.e., syngs). Methane, hydrogen, carbon monoxide, carbon dioxide, and hydrogen sulfide are primary components of the produced gas. The produced gas can have various uses, e.g., it may serve as a fuel for a gas turbine for electricity generation, or it can be used as a chemical feedstock for a conversion to synthetic fuels. The product gas composition depends on the coal geology and gasification parameters. The diversity of the conditions, factors, and structure of individual coal seams hampers the transfer of the UCG process knowledge [1-3].

The UCG reactor can be divided into four zones (i.e., the oxidation zone, reducing zone, and drying and pyrolysis zone). The reactions take place in these zones depending on the coal geology, the composition of the gasification agent, and the coal seam temperature. The oxidation reactions increase the coal seam temperature to above $900^{\circ} \mathrm{C}$. The reduction reactions generate produced gas (i.e., synthetic gas - syngas) in a temperature range from 550 to $900{ }^{\circ} \mathrm{C}$. The coal seam is initially dried and then pyrolyzed at tem- peratures ranging from 200 to $550^{\circ} \mathrm{C}$. The product gas is cleaned and stored after the extracting process from the product well 4,6 . The scheme of the UCG process is shown in Figure 1.

A decisive role throughout the UCG process is correctly identifying the geology of the area. Impermeable over/underlying strata that have low porosity and less deformation are the most suitable. They act as a seal between the surrounding rock layers and the gasified coal seam [7. The cavity growth in time and space has a random nature due to the impact of the surrounding rock and lack of information to control the UCG process. Fracturing and cracks are created inside the gasified coal seam and surrounding rocks when the underground cavity grows. It was identified that operational conditions (i.e., operation times, feed gases, and flow rates on gasification) have significantly affected the fracture occurrence, cavity growth, rack behavior, and coal gasification efficiency [8]. An effective pressure control system and also a gas production controlling (i.e., calorific value and volumetric production rate) by the proper composition and volume of the gasification agent are recommended to implement in the UCG process 9 .

Numerical models, as a tool for optimizing the technologies, are used to simulate the processes. The paper [10] reviews the approaches, key concepts, assumptions, and limitations of models (e.g., the packed bed model, the channel model, and the coal slab model) for a prediction of a cavity growth and gas production in the UCG process. The results of this study showed that currently used computing 3D models are very simple (i.e., the details of the physical and chemical models are not considered), and developing the UCG 


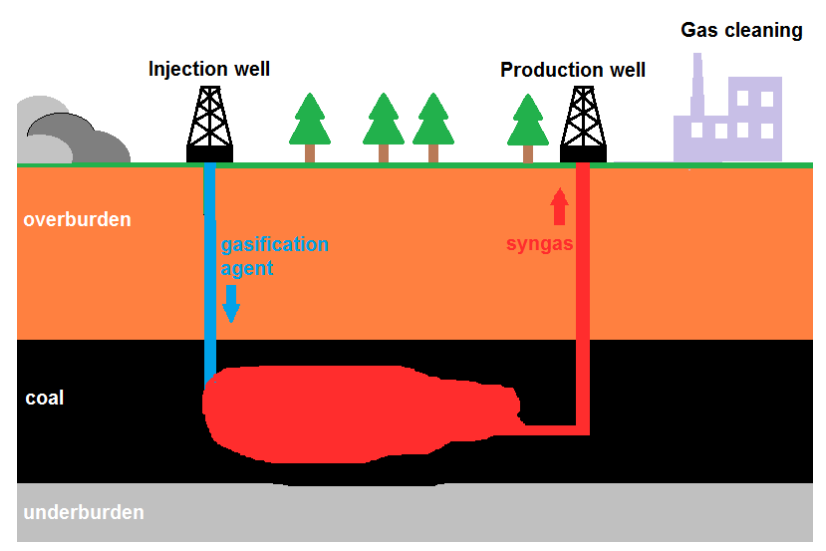

Figure 1. The scheme of the UCG process.

model requires an understanding of physical theory and correctly interpreting of the operating and laboratory results. The paper [11] describes the analysis of the temperature field in the gasified coal layers by a model experiment in the laboratory gasifier and the two-dimension nonlinear and dynamic mathematical models. The temperature of the coal layer is considered steady in the thickness direction and unsteady (i.e., in time) along the strike and slope of the coal seam. The results showed that the relative error between the calculated value and the measured value was below $15 \%$, except for the measured points near the flameworking face. The combustion mathematical modeling and in situ gasification was described in [12]. Chemical reactions in multiphase porous media were simulated in this work. The influence of the oxidant injection position (i.e., bottom and top position) to determine buoyant forces and product gas properties by a dynamic model of an underground cavity partially filled with an ash bed is described in [13. This dynamic model simulates the combined effect of transport phenomena (i.e., heat and mass) and chemical reactions during the UCG process. The mathematical model in the energy balance form is described in [14. The task of this model is realizing energy balances and estimating the efficiency of the hydrogen conversion from syngas.

The development of information concerning the efficiency of processes, either through calculation from the first principles or by experimentation, also associates the development of the material and energy balance calculations. Recently, incorporating material balance principles in industrial and agricultural performance measurement systems with pollutant factors has been on the rise. The issue of eco-efficiency measurement adjusted for pollution, taking into account materials flow conditions and the material balance principle requirements to provide more precise measures of performance, is described in paper [15]. In this work, a new approach by integrating a slacks-based measure to enhance the Malmquist Luenberger Index by a material balance condition was presented. New approaches of material balance calculations, namely graph and neuro-fuzzy are described in [16. Result show that the multimodel of both methods was suitable. The paper [17] described a new comprehensive version of the flowing material balance to address errors in the hydrocarbons-in-place estimation. The developed method was used to reasonably determine the original volumes of hydrocarbons in place in both the conventional and unconventional reservoirs.. A new zero-dimensional (tank) material balance equation for predicting the reservoir performance has been described in [18]. This material balance is directly applicable for the analysis of liquid-rich (wet and retrograde) gas reservoirs in form of an equivalent gas molar density function.. The density-based equation allows it be directly expressed as an extension of the dry gas material balance equation. The mass-balance calculations have been used in computation (estimation) of the accumulation of soil organic matter, transformation of pedogenic $\mathrm{Fe}$ and $\mathrm{Al}$, and net losses of the main elements (i.e., Ca, Mg, K, Na, Fe, Al, Mn, and $\mathrm{Si}$ ) in paper [19]. Elemental losses due to deglaciation and exposure to the weathering environment were calculated in this paper. The results show that extensive mineral weathering resulted in significant leaching losses of Si, major base cations, and Al. The paper [20] describes the material balance calculated for cocombustion of the high-watered oil sludge and the separated oil product composition. In this paper, the content of moisture and ash of the combustible working material was used to determine the elemental composition of the petroleum product. The materialbalance equation for the estimation of the gas and condensate in place in shale-gas-condensate reservoirs has been described in 21. The task of this materialbalance is estimating the critical time for using the gas injection when the condensate buildup represents a problem. It considers the stress-dependency of porosity and permeability and also takes into account the effects of adsorbed, free, and dissolved gas-condensate production. The paper [22] described the material balance of organic matter for initial rock sample (Domanic black shale) and after a thermal treatment at 300 and $500{ }^{\circ} \mathrm{C}$. The amounts of generated liquid hydrocarbon at these temperatures are presented. The paper 23 describes equations of mass and energy balances for the solid and gas phases in the UCG process. The heat transfer by conduction in the solid phase and convection in the gas phase is considered. The results of the longwall generator method showed that the energy content of the output gas depends on the coal seam dimensions and the applied pressure gradient. The use of the mass and heat balance calculations for thin coal seams in faulting zones of the coal basin is described in [24]. These calculations are used to analyze the effectiveness of the UCG process and to obtain quantitative and qualitative indicators of the output parameters for the UCG products prediction. The mass balance is based on a mathematical model of the physical and chemical processes and takes into 
account phases of individual substances (i.e., solid, liquid, and gaseous phases).

This paper described the proposal of the mate$\mathrm{rial} / \mathrm{mass}$ balance of the UCG process due to the information given above. This balance is verified by measurements realized under laboratory conditions on the two physical models (i.e., ex-situ reactors). The total material balance will be based on the balance of the input (i.e., coal and gasification agent) and output components (i.e., unburned coal, condensate, ash, and produced gas). The elemental material balances will be based on the balance of elements such as C (carbon), H (hydrogen), N (nitrogen), O (oxygen), and $\mathrm{S}$ (Sulphur), which are dominant in the mass components of the total material balance.

\section{Material Balance}

The subject of research (i.e., system) can be defined as a volume in space with set boundaries corresponding to the purpose of the research. The system includes a quantity of material and an assembly of equipment where it is necessary to supply energy (e.g., in heat form) to transform the material from the initial to the final state (i.e., a mass of the system is variable with time) [25].

The laboratory UCG process may be marked as a batch process because the raw material is added to the ex-situ reactor at the beginning of the process and kept there until the desired final state is reached. Chemical reactions taking place in this ex-situ reactor involve the separation and combination of molecules and elements to form new chemical substances (e.g., synthetic gas) during the UCG process. In this paper, a material balance is used as an application of conservation of mass in the UCG process. The task of this material balance is to determine mass flow by accounting for material entering and leaving a system (ex-situ UCG reactor). The entering materials in the process are the coal and gasification agent (i.e., a mixture of air and oxygen) and the leaving materials are the product gas (i.e., syngas), ash, condensate, and unburned coal. The total mass flow that enters the process must be equal to the overall mass flow that leaves process. A schematic drawing of the material balance of the UCG process in the ex-situ reactor is shown in Figure 2. Since total mass is conversed, a general mass balance in the overall UCG process can be written as follows:

$$
\begin{array}{r}
G_{\text {coal }}+G_{\text {air }}+G_{\text {oxygen }}= \\
G_{\text {coal }, \text { unburned }}+G_{\text {ash }}+G_{\text {syngas }}+G_{\text {condensate }}
\end{array}
$$

where $G_{\text {coal }}$ is the mass of input coal $(\mathrm{kg}), G_{\text {air }}$ is the mass of air $(\mathrm{kg}), G_{\text {oxygen }}$ is the mass of oxygen $(\mathrm{kg}), G_{\text {coal,unburned }}$ is the mass of unburned coal $(\mathrm{kg})$, $G_{a s h}$ is the mass of ash $(\mathrm{kg}), G_{\text {syngas }}$ is the mass of product gas $(\mathrm{kg})$, and $G_{\text {condensate }}$ is the mass of condensate $(\mathrm{kg})$.

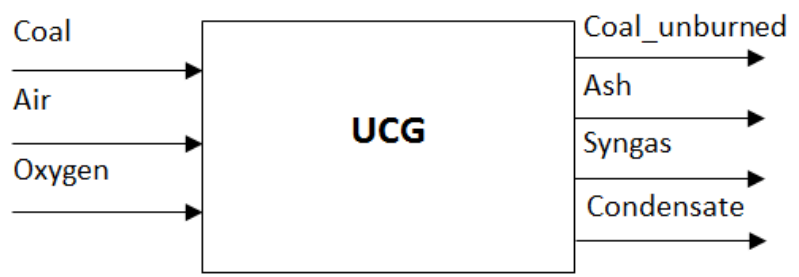

FigURE 2. Scheme of material balance.

Chemical reactions are common occurrences in the production and processing of materials. One of the expected outputs from the UCG process is the higher temperature that ensures the realization of the chemical reactions needed for the syngas creation. The equation of the material balance can be written based on the principle of the conservation of atoms as species, or as elements. An atomic species balance is based on the principle that input equals output because atomic species can neither be generated nor consumed in chemical reactions 26, 27. The balance of atomic species for considered elements $\mathrm{C}$ (carbon), $\mathrm{H}$ (hydrogen), N (nitrogen), O (oxygen), and S (Sulphur) has the following form

$$
\sum_{i=1}^{m} G_{x, \text { input }_{i}}=\sum_{j=1}^{n} G_{x, \text { output }_{j}}
$$

where $G_{x, \text { input }_{i}}$ is the mass of $x$-th chemical element (i.e., C, H, N, O, and $\mathrm{S}$ ) in the individual input materials (i.e., input coal, air, and oxygen) (kg), and $G_{x, \text { output }_{j}}$ is the mass of $x$-th chemical element (i.e., $\mathrm{C}, \mathrm{H}, \mathrm{N}, \mathrm{O}$, and $\mathrm{S}$ ) in the individual output materials (i.e., unburned coal, ash, and gas) (kg).

Table 1 shows the representation of atoms in the mass of entering and leaving materials. Similarly, Table 2 shows the representation of atoms in a mass of syngas. These representations were determined according to the chemical composition of particular entering and leaving materials. The chemical composition of syngas (i.e., without $\mathrm{SO}_{2}$ ) was determined by the type and percentage content of measured gas components during laboratory experiments. The mass volume of $\mathrm{SO}_{2}$ in the syngas was calculated by a difference of $\mathrm{S}$ atoms between the input coal and unburned coal.

The mass of $x$-th chemical element in syngas was determined from individual chemical compounds (i.e., $\mathrm{CO}, \mathrm{CO}_{2}, \mathrm{H}_{2}, \mathrm{CH}_{4}, \mathrm{SO}_{2}, \mathrm{O}_{2}$, and $\mathrm{N}_{2}$ ) where this chemical element is found. For example, we can calculate the mass of $\mathrm{C}$ chemical element from chemical compounds of syngas according to

$$
G_{C, \text { syngas }}=\sum_{k=1}^{3} V_{k, \text { syngas }} \cdot \rho_{k} \cdot \frac{M_{C}}{M_{k}}
$$

where $G_{C \text {,syngas }}$ is the mass of $\mathrm{C}$ chemical element in syngas $(\mathrm{kg}), V_{k, \text { syngas }}$ is the volume of $k$-th chemical compound $\left(\mathrm{m}^{3}\right), \rho_{k}$ is the density of $k$-th chemical 


\begin{tabular}{cccccccc}
\hline & \multicolumn{3}{c}{ entering material } & \multicolumn{4}{c}{ leaving material } \\
\cline { 2 - 7 } Atom & coal & air & oxygen & unburned coal & ash & syngas & condensate \\
\hline $\mathrm{C}$ & yes & no & no & yes & no & yes & no \\
$\mathrm{H}$ & yes & no & no & yes & no & yes & yes \\
$\mathrm{N}$ & yes & yes & no & yes & no & yes & no \\
$\mathrm{O}$ & yes & yes & yes & yes & no & yes & yes \\
$\mathrm{S}$ & yes & no & no & yes & no & yes & no \\
\hline
\end{tabular}

TABLE 1. The representation of considered atoms in entering and leaving materials

\begin{tabular}{cccccccc}
\hline Atom & $\mathrm{CO}$ & $\mathrm{CO}_{2}$ & $\mathrm{H}_{2}$ & $\mathrm{CH}_{4}$ & $\mathrm{SO}_{2}$ & $\mathrm{O}_{2}$ & $\mathrm{~N}_{2}$ \\
\hline $\mathrm{C}$ & yes & yes & no & yes & no & no & no \\
$\mathrm{H}$ & no & no & yes & yes & no & no & no \\
$\mathrm{N}$ & no & no & no & no & no & no & yes \\
$\mathrm{O}$ & yes & yes & no & no & yes & yes & no \\
$\mathrm{S}$ & no & no & no & no & yes & no & no \\
\hline
\end{tabular}

TABLE 2. The representation of considered atoms in syngas

compound $\left(\mathrm{kg} \cdot \mathrm{m}^{-3}\right), M_{k}$ is the molar mass of $k$-th chemical compound $\left(\mathrm{g} \cdot \mathrm{mol}^{-1}\right), M_{C}$ is the molar mass of $\mathrm{C}$ chemical element $\left(\mathrm{g} \cdot \mathrm{mol}^{-1}\right)$, and $k$ is the index of the chemical compound where $\mathrm{C}$ is found (i.e., $\mathrm{CO}$, $\mathrm{CO}_{2}$, and $\left.\mathrm{CH}_{4}\right)$.

\section{VERIFICATION OF MATERIAL BALANCE}

The material balance of the UCG process was verified using data obtained from four experimental measurements. These measurements were realized in two ex-situ reactors. A description of ex-situ reactors, experimental measurements, and the evaluation of these measurements by total and atoms material balance is in the following subsections.

\subsection{EX-SITU REACTORS AND EXPERIMENTAL MEASUREMENTS}

Ex-situ reactors were created for the investigation of the UCG process. These ex-situ reactors were created in a geometric similarity to a real coal seam. The coal cubes or broken coal represent the coal seam model. The clays, isolation material (i.e., sibral and nobasil), and a mixture of gravel and water glass represent the surrounding rock. These components were embedded in ex-situ reactors before the experimental gasification. Ex-situ reactors include vessel and lid. The vessel of the first ex-situ reactor has a half-round shape. Its length is $3000 \mathrm{~mm}$, and height is $500 \mathrm{~mm}$. The vessel of the second ex-situ reactor has a shape of a large steel box. Dimensions of this ex-situ reactor are $5000 \times 1500 \times 500 \mathrm{~mm}$ (i.e., length $\times$ width $\times$ height $).$

The UCG process realized in created ex-situ reactors is based on the principle of a controlled gasification agent (i.e., air and oxygen) supply to the burning coal seam model and the extraction of syngas. The laboratory UCG process scheme is shown in Figure 3. The flow of the gasification agent and syngas, the syngas compositions, and temperatures of coal and surrounding rock were measured during laboratory experiments. The principal scheme of ex-situ reactors is shown in Figure 4. The temperature and gas composition were measured using measuring probes designed for a gasification process analysis.

The six experiments were realized in described exsitu reactors - four experiments in the first ex-situ reactor and two experiments in the second ex-situ reactor. These experiments were different in the coal seam model. The cross-sectional design of the coal seam model for the first experiment is shown in Figure $5 \mathrm{a}$ and for the second experiment in Figure 5b. The first and second measurement were realized in the first ex-situ reactor. The cross-sectional design of the coal seam model for the third experiment is shown in Figure 5 and for the fourth experiment in Figure 5 d. The third and fourth measurement were realized in the second ex-situ reactor. The cross-sectional design of the coal seam model for the fifth and sixth experiment is shown in Figure 55. The fifth and sixth measurement were realized in the first ex-situ reactor and the individual components volume of these two experiments was different.

The physical model of the coal seam consisted of broken coal with a total weight of $521 \mathrm{~kg}$ in the first experiment. There was $167 \mathrm{~kg}$ of the unburned crushed coal after the gasification process. Coal cubes with a total weight of $532 \mathrm{~kg}$ were used in the second experiment. In total, $62 \mathrm{~kg}$ of unburned coal remained after the gasification process. Coal cubes with a total weight of $702 \mathrm{~kg}$ were used in the third experiment. In total, $147 \mathrm{~kg}$ of unburned coal remained after the gasification process. The ex-situ reactor was filled with coal cubes with a total weight of $766 \mathrm{~kg}$ in the fourth experiment. In total, $1335 \mathrm{~kg}$ of unburned coal remained after the gasification process. Coal cubes with a total weight of $214 \mathrm{~kg}$ were used in the fifth 
Flow

measurement

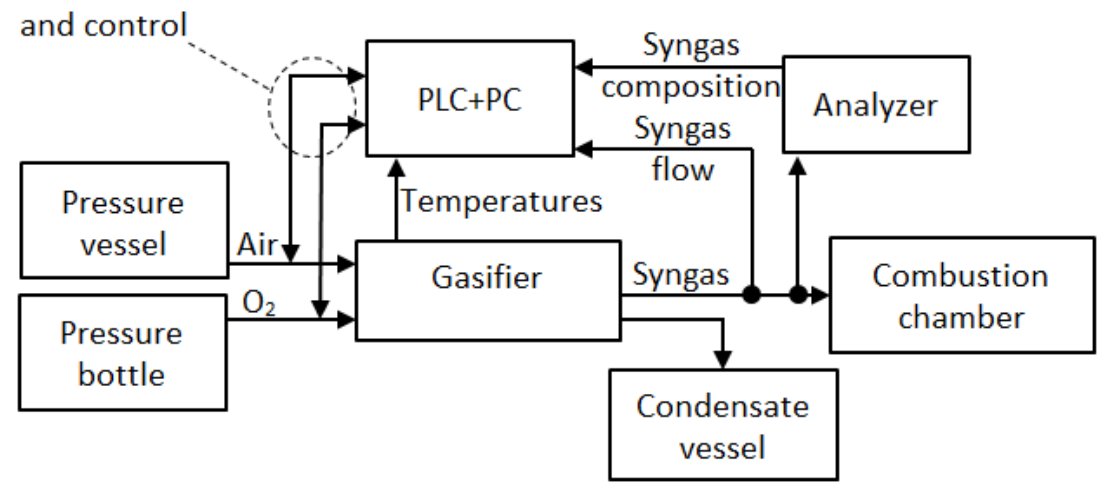

Figure 3. Scheme of the laboratory UCG process.

a)
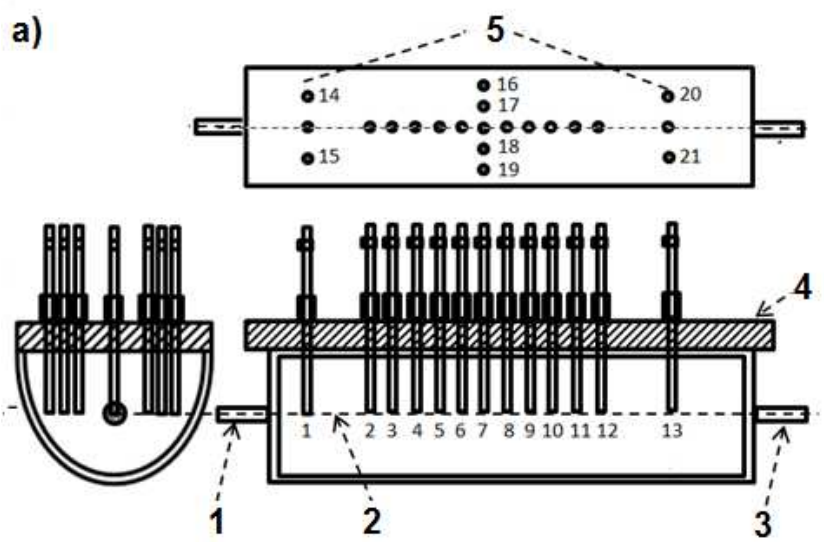

b)
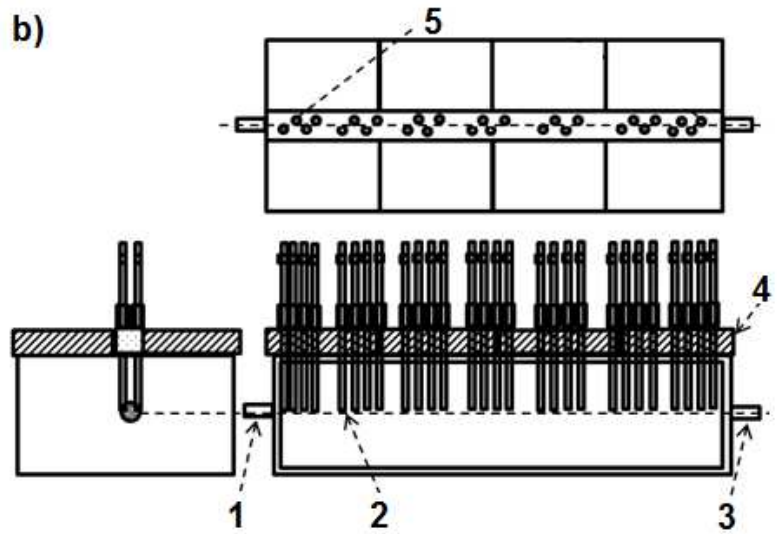

Figure 4. Principal scheme of ex-situ reactors (Legend: (a) the first ex-situ reactor, (b) the second ex-situ reactor, 1 - gasification agent supply, 2 - gasification channel, 3 - exhaust gas, 4 - the lid of the generator, 5 - sounds for analysis).
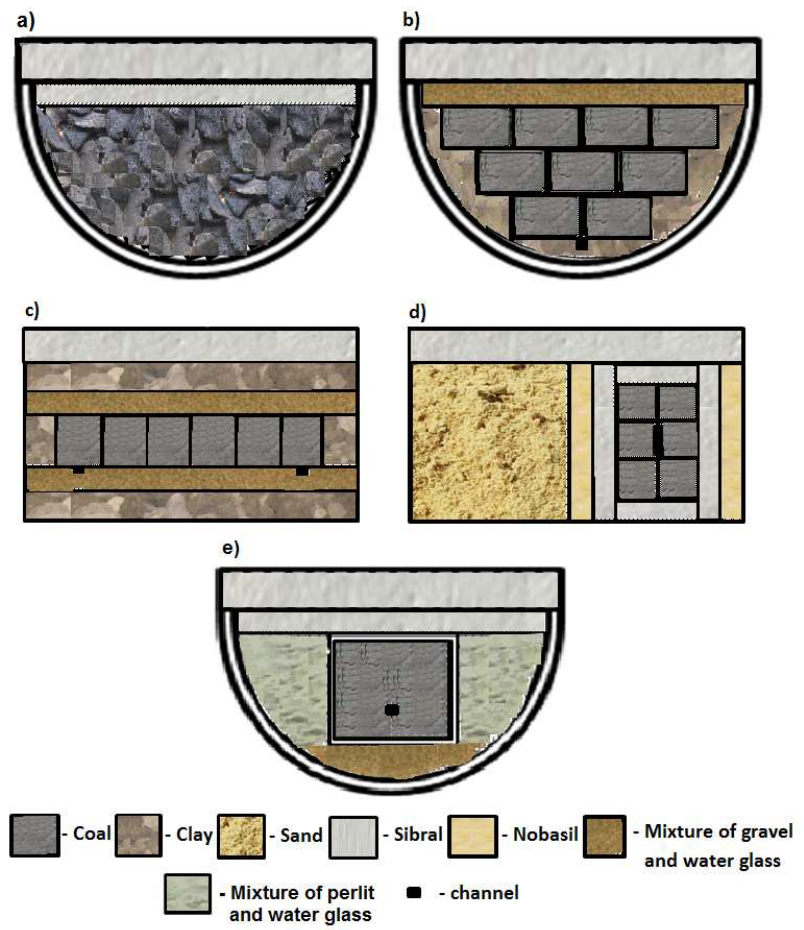

Figure 5. The cross-sectional design of the coal seam model. 


\begin{tabular}{cccccccc}
\hline & \multirow{2}{*}{ Moisture (\%) } & \multirow{2}{*}{ Ash (\%) } & C & H & N & O & S \\
\hline input coal & 20.4 & 24.1 & 35.9 & 3.1 & 0.6 & 15 & 0.9 \\
\hline unburned coal & 0 & 30.4 & 45.1 & 3.9 & 0.7 & 18.8 & 1.1 \\
\hline
\end{tabular}

TABLE 3. The coal analysis

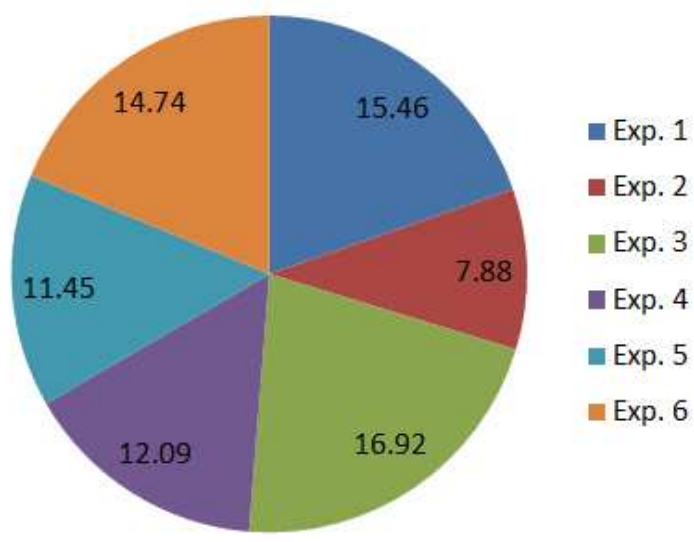

Figure 6. Percentage of losses in experiments.

experiment. No unburned coal remained after this experiment. Coal cubes with a total weight of $472 \mathrm{~kg}$ were used in the sixth experiment. In total, $66 \mathrm{~kg}$ of unburned coal remained after the gasification process.

Flows of gasification agents and syngas, the mass flow rate of condensate, and chemical composition of syngas (i.e., $\mathrm{CO}, \mathrm{CO}_{2}, \mathrm{CH}_{4}, \mathrm{H}_{2}$, and $\mathrm{O}_{2}$,) were measured in these experiments. The Lignite coal was used for the creation of a coal model. The gasified coal analysis for the input and unburned coal is shown in Table 3

\subsection{The Simulation RESUlts}

The values of general and atomic species mass balance were calculated based on measured components as the flow of gasification agent and syngas, the gasification agent and syngas composition, mass of condensate, and mass of input and unburned coal. The values of mass balance for individual experiments are shown in Tables 4, 9, A loss component was also added to the tables. This component was determined as the difference between entering and leaving material of individual mass balance components. The percentage of losses in individual experiments is shown in Figure 6 . The difference between entering and leaving material can be caused by gasification agent leak on the input side (i.e., atoms $\mathrm{N}$ and $\mathrm{O}$ ) and syngas leak on the output side (i.e., atoms $\mathrm{C}, \mathrm{H}, \mathrm{N}, \mathrm{O}$, and $\mathrm{S}$ ).

The highest amount of losses was found in the first (i.e. $15.46 \%$ ) and third (i.e. $16.92 \%$ ) experiment. It can be caused by a type of gasified coal (i.e., the broken coal was gasified at the first experiment) and the surrounding rock type (i.e., sibral, clay and a mixture of gravel and water glass at the third experiment).

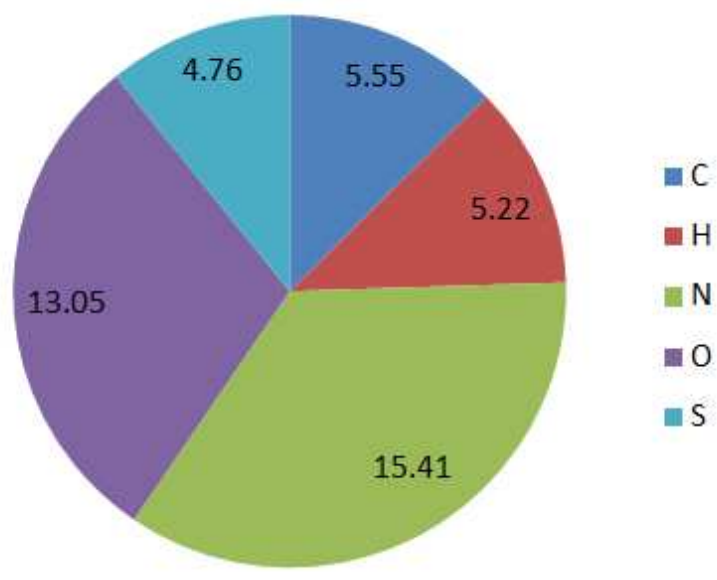

Figure 7. Average percentage of atom losses.

The broken coal caused the gasification agent and syngas leaks through the coal seam, and surrounding rock (i.e., a mixture of gravel and water glass) was cracked under the influence of high temperatures. The syngas and mainly gasification agent leaked through this mixture. The average percentage of atom loss is shown in Figure 7 where the highest atoms losses were for components $\mathrm{N}$ (i.e. $15.41 \%$ ) and $\mathrm{O}$ (i.e. $13.05 \%$ ). It confirms that the largest loss were in the pipeline at the inlet of the reactor.

Figure 8 showed that losses for components $\mathrm{N}$ and $\mathrm{O}$ were not the same in individual experiments, except for the first experiment, where they were approximately equal (i.e., $17.35 \%$ for component $\mathrm{O}$ and $17.45 \%$ for component $\mathrm{N})$. The loss of the component $\mathrm{O}$ was the highest in the fourth and fifth experiment, but the loss of the component $\mathrm{N}$ was the highest at the second, third, and sixth experiment. We assume that the leaks were mainly through the $\mathrm{O}_{2}$ pipeline at the fourth and fifth experiment and the air pipeline at the second, third, and sixth experiment. The mass balance calculation showed that the lowest syngas losses were measured for the $\mathrm{C}$ and $\mathrm{H}$ atoms. These atoms in syngas were obtained only from the gasified coal.

\section{Summary and Conclusions}

This paper describes the proposal of a general and atomic species mass balance for improving the knowledge about the UCG process. The information about the composition of the entering and leaving materials in the UCG process is significant for an optimization and efficiency of the process.. This balance can pro- 


\begin{tabular}{cccc|ccccc}
\hline \multirow{2}{*}{ Balance } & \multicolumn{6}{c}{ entering material $(\mathrm{kg})$} & \multicolumn{5}{c}{ leaving material $(\mathrm{kg})$} & losses \\
\cline { 2 - 7 } & coal & air & oxygen & unburned coal & ash & gas & condensate & \\
\hline General & 521 & 1504.13 & 21.42 & 167 & 75.18 & 1403.23 & 84.75 & 316.4 \\
\hline $\mathrm{C}$ & 186.98 & 0 & 0 & 75.31 & 0 & 95.49 & 0 & 16.18 \\
$\mathrm{H}$ & 27.95 & 0 & 0 & 6.5 & 0 & 9.75 & 9.44 & 2.25 \\
$\mathrm{~N}$ & 3 & 1153.65 & 0 & 1.21 & 0 & 952.52 & 0 & 202.93 \\
$\mathrm{O}$ & 172.4 & 350.48 & 21.42 & 31.39 & 0 & 342.95 & 75.56 & 94.41 \\
$\mathrm{~S}$ & 4.68 & 0 & 0 & 1.88 & 0 & 2.52 & 0 & 0.27 \\
\hline
\end{tabular}

TABLE 4. The value of general and atomic balance in the first experiment

\begin{tabular}{cccc|ccccc}
\hline \multirow{2}{*}{ Balance } & \multicolumn{3}{c}{ entering material $(\mathrm{kg})$} & \multicolumn{5}{c}{ leaving material $(\mathrm{kg})$} \\
\cline { 2 - 8 } & coal & air & oxygen & unburned coal & ash & gas & condensate & \\
\hline General & 532 & 903.51 & 129.6 & 32 & 118.83 & 1237.97 & 53 & 123.3 \\
\hline C & 190.93 & 0 & 0 & 14.43 & 0 & 170.17 & 0 & 6.33 \\
H & 28.54 & 0 & 0 & 1.25 & 0 & 20.64 & 5.89 & 0.76 \\
N & 3.07 & 692.98 & 0 & 0.23 & 0 & 599.61 & 0 & 96.21 \\
O & 176.04 & 210.53 & 129.6 & 6.01 & 0 & 443.35 & 47.11 & 19.69 \\
S & 4.78 & 0 & 0 & 0.36 & 0 & 4.19 & 0 & 0.22 \\
\hline
\end{tabular}

TABLE 5. The value of general and atomic balance in the second experiment

\begin{tabular}{cccc|ccccc}
\hline \multirow{2}{*}{ Balance } & \multicolumn{3}{c}{ entering material $(\mathrm{kg})$} & \multicolumn{5}{c}{ leaving material $(\mathrm{kg})$} \\
\cline { 2 - 7 } & coal & air & oxygen & unburned coal & ash & gas & condensate & \\
\hline General & 702 & 3220.74 & 129.6 & 147 & 124.99 & 2979.69 & 114.84 & 685.83 \\
\hline $\mathrm{C}$ & 251.94 & 0 & 0 & 66.29 & 0 & 174.97 & 0 & 10.68 \\
$\mathrm{H}$ & 37.66 & 0 & 0 & 5.72 & 0 & 18.19 & 12.76 & 0.99 \\
$\mathrm{~N}$ & 4.05 & 2470.28 & 0 & 1.06 & 0 & 1819.82 & 0 & 653.44 \\
$\mathrm{O}$ & 232.3 & 750.46 & 129.6 & 27.63 & 0 & 962.23 & 102.08 & 20.42 \\
$\mathrm{~S}$ & 6.3 & 0 & 0 & 1.66 & 0 & 4.47 & 0 & 0.18 \\
\hline
\end{tabular}

TABLE 6. The value of general and atomic balance in the third experiment

\begin{tabular}{cccc|ccccc}
\hline \multirow{2}{*}{ Balance } & \multicolumn{3}{c}{ entering material $(\mathrm{kg})$} & \multicolumn{5}{c}{ leaving material $(\mathrm{kg})$} \\
\cline { 2 - 8 } & coal & air & oxygen & unburned coal & ash & gas & condensate & \\
\hline General & 766 & 1801.16 & 129.6 & 133.5 & 144.55 & 2043.06 & 49.68 & 325.97 \\
\hline $\mathrm{C}$ & 274.91 & 0 & 0 & 60.21 & 0 & 198.52 & 0 & 16.18 \\
$\mathrm{H}$ & 41.09 & 0 & 0 & 5.2 & 0 & 28.15 & 5.52 & 2.23 \\
$\mathrm{~N}$ & 4.41 & 1381.48 & 0 & 0.97 & 0 & 1296.01 & 0 & 88.91 \\
$\mathrm{O}$ & 253.48 & 419.69 & 129.6 & 25.09 & 0 & 515.32 & 44.16 & 218.19 \\
$\mathrm{~S}$ & 6.88 & 0 & 0 & 1.51 & 0 & 5.05 & 0 & 0.32 \\
\hline
\end{tabular}

TABLE 7. The value of general and atomic balance in the fourth experiment

\begin{tabular}{cccc|ccccc}
\hline \multirow{2}{*}{ Balance } & \multicolumn{2}{c}{ entering material $(\mathrm{kg})$} & \multicolumn{5}{c}{ leaving material $(\mathrm{kg})$} & losses \\
\cline { 2 - 7 } & coal & air & oxygen & unburned coal & ash & gas & condensate & \\
\hline General & 214 & 1179.02 & 129.6 & 0 & 51.71 & 1285.53 & 10.97 & 174.41 \\
\hline C & 76.8 & 0 & 0 & 0 & 0 & 72.55 & 0 & 4.25 \\
H & 11.48 & 0 & 0 & 0 & 0 & 9.51 & 1.22 & 0.75 \\
N & 1.23 & 904.3 & 0 & 0 & 0 & 851.27 & 0 & 54.26 \\
O & 70.81 & 274.72 & 129.6 & 0 & 0 & 350.39 & 9.75 & 115 \\
S & 1.92 & 0 & 0 & 0 & 0 & 1.82 & 0 & 0.11 \\
\hline
\end{tabular}

TABLE 8. The value of general and atomic balance in the fifth experiment 


\begin{tabular}{|c|c|c|c|c|c|c|c|c|}
\hline \multirow{2}{*}{ Balance } & \multicolumn{3}{|c|}{ entering material $(\mathrm{kg})$} & \multicolumn{4}{|c|}{ leaving material $(\mathrm{kg})$} & \multirow{2}{*}{ losses } \\
\hline & coal & air & oxygen & unburned coal & ash & gas & condensate & \\
\hline General & 472 & 1946.06 & 129.6 & 66 & 94.01 & 2001.15 & 10.97 & 375.54 \\
\hline $\mathrm{C}$ & 169.4 & 0 & 0 & 29.76 & 0 & 130.01 & 0 & 9.62 \\
\hline $\mathrm{H}$ & 25.32 & 0 & 0 & 2.57 & 0 & 20.01 & 1.22 & 1.53 \\
\hline $\mathrm{N}$ & 0 & 1492.61 & 0 & 0 & 0 & 1159.88 & 0 & 332.74 \\
\hline $\mathrm{O}$ & 156.19 & 453.45 & 129.6 & 12.4 & 0 & 687.98 & 9.75 & 29.11 \\
\hline $\mathrm{S}$ & 4.24 & 0 & 0 & 0.74 & 0 & 3.28 & 0 & 0.21 \\
\hline
\end{tabular}

TABLE 9. The value of general and atomic balance in the sixth experiment
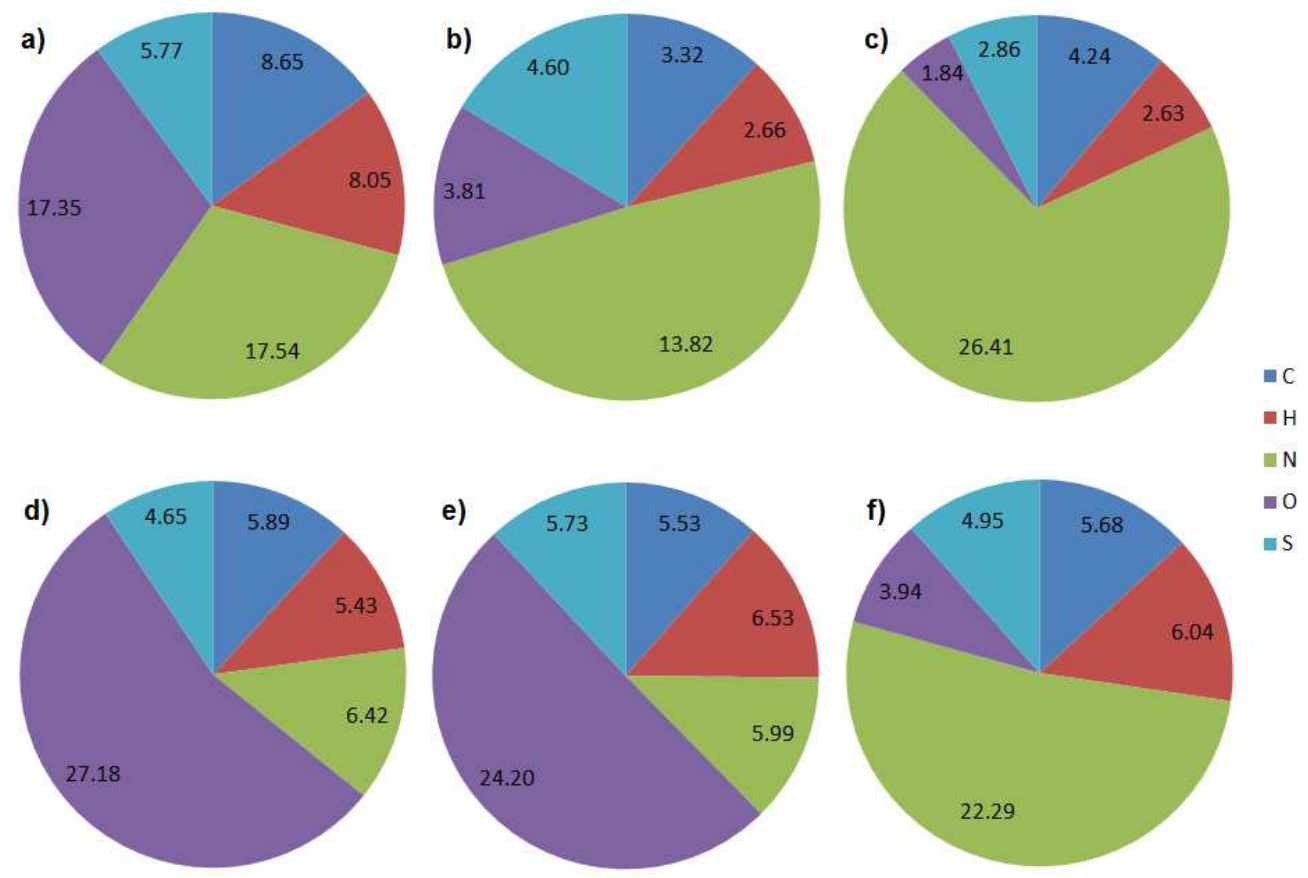

Figure 8. Percentage of atom losses in experiments (a) the first experiment, b) the second experiment, c) the third experiment, d) the fourth experiment, e) the fifth experiment, f) the sixth experiment).

vide information about the coal mass gasified (i.e., cavity formation) through the UCG process by watching atoms, e.g., $\mathrm{C}$ atom in syngas. The information about $\mathrm{C}$ atom can be obtained from the input coal on the input side and from syngas (i.e., molecular compounds,such as $\mathrm{CO}, \mathrm{CO}_{2}$, and $\mathrm{CH}_{4}$ ) on the output side.

The proposed mass balance was verified on the data obtained from six laboratory experiments. There is a visible difference between the input and output side of the mass balance in results from the described experiments. An examination of the overall mass flow clearly indicates that the process suffers from a mass loss:

- The flow meter on one of the streams is faulty.

- A leak of the gasification agent or syngas is present.

- The syngas analysis is wrong.

We must avoid these failures to propose a more precise calculation of proposed mass balance in the UCG process. The crushed coal was causing a higher syngas leak through the generator. For this reason, it is imperative to know the coal seam permeability and cracks in real and laboratory conditions.

The achieved accuracy of the calculation for the mass balance components confirmed that the proposed approach is suitable for testing under real conditions. Results of the mass balance in real conditions could determine the amount of gasifying coal at a specific time (i.e., cavity growth). The information about the syngas composition and proportion of important atoms can be used in the control of the UCG process, e.g., control of the gasification agent ratio (i.e., the ratio of air, $\mathrm{O}_{2}$, and also $\mathrm{H}_{2} \mathrm{O}$ ) to improve the syngas calorific value. It will also enable the proposal of new approaches to the control of the UCG process.

\section{ACKNOWLEDGEMENTS}

This work was supported by the Slovak Research and Development Agency under the contracts No. APVV-140892 and APVV-18-0526. 


\section{REFERENCES}

[1] A. Bhutto, A. Bazmi, G. Zahedi. Underground coal gasification: From fundamentals to applications. Progress in Energy and Combustion Science 39(1):189 214, 2013. DOI:10.1016/j.pecs.2012.09.004

[2] A. Uppal, A. Bhatti, E. Aamir, et al. Control oriented modeling and optimization of one dimensional packed bed model of underground coal gasification. Journal of Process Control 24(1):269 - 277, 2014. DOI:10.1016/j.jprocont.2013.12.001.

[3] J. Kačur, M. Durdán, M. Laciak, P. Flegner. A comparative study of data-driven modeling methods for soft-sensing in underground coal gasification. Acta Polytechnica : journal of advanced engineering 59(4):322 - 351, 2019. DOI:10.14311/AP.2019.59.0322

[4] M. Laciak, K. Kostúr, M. Durdán, et al. The analysis of the underground coal gasification in experimental equipment. Energy 114:332 - 343, 2016. DOI:10.1016/j.energy.2016.08.004

[5] K. Kostúr, M. Laciak, M. Durdán. Some influences of underground coal gasification on the environment. Sustainability 10(5):1 - 31, 2018. DOI:10.3390/su10051512

[6] E. Škvareková, G. Wittenberger, M. Šofránko. Tar related issues in underground coal gasification. Acta Montanistica Slovaca 21(4):298 - 305, 2016.

[7] D. Mohanty. An overview of the geological controls in underground coal gasification. IOP Conference Series: Earth and Environmental Science 76(1):1 - 8, 2017. DOI:10.1088/1755-1315/76/1/012010.

[8] F. Su, K. Itakura, G. Deguchi, K. Ohga. Monitoring of coal fracturing in underground coal gasification by acoustic emission techniques. Appl Energy 189:142 156, 2017. DOI:10.1016/j.apenergy.2016.11.082

[9] P. Mocek, M. Pieszczek, J. Swiadrowski, et al. Pilotscale underground coal gasification (UCG) experiment in an operating mine wieczorek in poland. Energy 111:313 - 321, 2016. DOI:10.1016/j.energy.2016.05.087

[10] M. M. Khan, J. P. Mmbaga, A. S. Shirazi, et al. Modelling underground coal gasification-A review. Energies 8(11): 12603 - 12668, 2015. DOI:10.3390/en81112331

[11] L. Yang. The dynamic temperature field of two-stage underground coal gasification (UCG). Energy Sources, Part A: Recovery, Utilization, and Environmental Effects 28(7):667 - 680, 2006. DOI:10.1080/009083190951438.

[12] G. Perkins. Mathematical modelling of in situ combustion and gasification. Proc Inst Mech Eng, Part A: J Power Energy 232(1):56 - 73, 2018. DOI:10.1177/0957650917721595

[13] G. Perkins, V. Sahajwalla. Modelling of heat and mass transport phenomena and chemical reaction in underground coal gasification. Chemical Engineering Research and Design 85(3):329 - 343, 2007. DOI:10.1205/cherd06022

[14] A. Verma, B. Olateju, A. Kumar, R. Gupta. Development of a process simulation model for energy analysis of hydrogen production from underground coal gasification (ucg). Int J Hydrogen Energy 40(34):10705 - 10719, 2015. DOI:10.1016/j.ijhydene.2015.06.149
[15] B. Arabi, S. Doraisamy, A. Emrouznejad, A. Khoshroo. Eco-efficiency measurement and material balance principle: an application in power plants malmquist luenberger index. Annals of Operations Research 255(12):221 - 239, 2017. DOI:10.1007/s10479-015-1970-x

[16] A. V. Spesivtsev, M. L. Dudorova. Multimodel approach to calculating material balances of an enterprise in the medium of intellectual data-measuring systems. Russian Journal of non-ferrous metals 52(2):191 - 195, 2011. DOI:10.3103/S1067821211020106

[17] M. S. Shahamat, C. R. Clarkson. Multiwell, multiphase flowing material balance. SPE Reservoir Evaluation \& Engineering 21(2):445 - 461, 2018. DOI:10.2118/185052-PA.

[18] M. Zhang, L. F. Ayala. A density-based material balance equation for the analysis of liquid-rich natural gas systems. Journal of petroleum exploration and production technology 6(4):705 - 718, 2016. DOI:10.1007/s13202-015-0227-1

[19] D. Orhan, S. Huseyin. Effect of top sequences on geochemical mass balance and clay mineral formation in soils developed on basalt parent material under subhumid climate condition. Indian journal of Geo-Marine sciences 47(9):1809 - 1820, 2018.

[20] P. A. Timofeev. Material balance calculation of incineration plant for oily-waste combustion. Marine intellectual technologies 1(3):111 - 115, 2018.

[21] D. Orozco, R. Aguilera. Material-balance equation for stress-sensitive shale-gas-condensate reservoirs. SPE Reservoir evaluation $\&$ engineering 20(1):197 - 214, 2017. DOI:10.2118/177260-PA

[22] Y. V. Onishchenko, A. V. Vakhin, B. I. Gareev, et al. The material balance of organic matter of domanic shale formation after thermal treatment. Petroleum science and technology 37(7):756 - 762, 2019. DOI:10.1080/10916466.2018.1558247.

[23] W. K. Sawyer, L. Shuck. Numerical simulation of mass and energy transfer in the longwall process of underground gasification of coal. In Society of Petroleum Engineers, SPE Symposium on Numerical Simulation of Reservoir Performance, Los Angeles, California, p. 16. 1976. DOI:10.2118/5743-MS.

[24] V. Lozynskyi, R. Dichkovskiy, P. Saik, V. Falshtynskyi. Coal seam gasification in faulting zones (heat and mass balance study). Solid State Phenomena 277:66 - 79, 2018. DOI:10.4028/www.scientific.net/SSP.277.66

[25] A. E. Morris, G. Geiger, H. A. Fine. Handbook on Material and Energy Balance Calculations in Materials Processing. Wiley-TMS 3 edition, 2011. DOI:10.1002/9781118237786

[26] K. Balu, N. Satyamurthi, S. Ramalingam, B. Deebika. Problems on Material and Energy Balance Calculation. I K International Publishing House, 2009.

[27] N. Ghasem, R. Henda. Principles of Chemical Engineering Processes: Material and Energy Balances, Second Edition. CRC Press, 2014. 